\title{
The Electrophysiologic Effects of Quinidine in the Transplanted Human Heart
}

\author{
Jay W. Mason, Roger A. Winkle, Alan K. Rider, Edward B. Stinson, \\ and DONALD C. HARRISON \\ From the Division of Cardiology and the Department of Cardiovascular Surgery, Stanford \\ University School of Medicine, Stanford, California 94305
}

\begin{abstract}
A BSTRACT Using His bundle recording techniques, we examined direct and autonomically mediated conduction system effects of quinidine in five cardiac transplant recipients who have anatomically denervated hearts. We made control conduction interval and refractory period measurements, and then infused $10 \mathrm{mg} / \mathrm{kg}$ quinidine gluconate over a $20-\mathrm{min}$ period. At $30 \mathrm{~min}$, we determined the electrophysiologic changes induced by quinidine. Quinidine significantly increased the atrial-His $(\mathrm{AH})$ interval (from $97 \pm 9$ [SEM] to $108 \pm 7 \mathrm{~ms}, P<0.001)$, the His-ventricular (HV) interval (from $43.9 \pm 1$ to $52.8 \pm 3 \mathrm{~ms}, P<0.01$ ), the donor heart sinus cycle length (from $599 \pm 38$ to $630 \pm 56 \mathrm{~ms}, P<0.08)$, and the atrial effective refractory period (from $214 \pm 14$ to $241 \pm 11 \mathrm{~ms}, P<0.01$ ). Quinidine significantly decreased the innervated, remnant atrial sinus cycle length (from $847 \pm 104$ to $660 \pm 96 \mathrm{~ms}$, $P<0.01)$ and the blood pressure. The mean plasma concentration of quinidine at the time that electrophysiologic measurements were repeated was $4.37 \pm 0.449$ $\mu \mathrm{g} / \mathrm{ml}$. We conclude that quinidine's predominant sinus nodal and atrioventricular nodal effects in man are autonomically mediated and opposite to its direct actions upon these structures. On the other hand, quinidine's prevailing effect on atrial refractoriness and His-Purkinje conduction in man is direct.
\end{abstract}

\section{INTRODUCTION}

The effect of quinidine upon the human cardiac conduction system is controversial because quinidine has both direct and autonomically mediated electrophysiologic activities. Several investigators have attempted to identify these actions separately in animals (1-4). Studies in man, in which His bundle record-

Dr. Stinson is an Established Investigator of the American Heart Association.

Received for publication 7 July 1976 and in revised form 5 November 1976.

ing techniques were applied $(5,6)$, could not make this separation because of the subjects' intact cardiac innervation which permitted both actions to occur simultaneously. In one of these investigations, Hirschfeld and his colleagues (5) administered quinidine intravenously to patients with intact cardiac neural supply and found a decrease in the AH interval, but no changes in the HV interval or the spontaneous sinus cycle length after quinidine. Josephson et al. (6), using His bundle recording techniques to study the effects of intramuscular quinidine in patients with intact cardiac autonomic supply, found that quinidine produced decreases in the sinus cycle length and the $\mathrm{AH}$ time, and increases in the atrial effective refractory period and His-Purkinje conduction time. In neither of these electrophysiologic studies in humans, however, were the direct and autonomically mediated effects of quinidine separately identified.

Cardiac transplant recipients provide a unique model for studying the heart free of autonomic influences (7-11). In the present study, we examined the effects of quinidine administered intravenously to human cardiac allograft recipients to determine the drug's autonomic and direct conduction system actions.

\section{METHODS}

Five cardiac allograft recipients were studied 8-20 mo after transplantation. The study was approved by the Stanford Medical Committee on the Use of Human Subjects in Research, and each patient gave informed, written consent. These patients had had uncomplicated postoperative courses, and at the time of study, were in New York Heart Association Class I functional status and had no evidence of cardiac rejection or of extracardiac disease. All five patients had normal cardiac biopsies, right and left heart hemodynamic studies, and coronary and left ventricular angiograms within 6 mo of this investigation. Patients were catheterized in the postabsorptive state with no sedation, or light diazepam sedation. Atrial electrogram recordings were obtained with a $7 \mathrm{~F}$ quadripolar recording-stimulating electrode catheter positioned in the high right atrium via the right internal jugular, 
TABLE I

$A H, H V$, and QT Intervals, Atrial Cycle Lengths, and Blood Pressure, before, during, and after Quinidine Infusion*

\begin{tabular}{|c|c|c|c|c|c|c|c|}
\hline \multirow{2}{*}{$\begin{array}{l}\text { Patient } \\
\text { no. }\end{array}$} & \multirow{2}{*}{$\begin{array}{l}\text { Pacing } \\
\text { cycle } \\
\text { length } \ddagger\end{array}$} & \multirow{2}{*}{$\begin{array}{l}\text { Measure- } \\
\text { ment } \$\end{array}$} & \multirow{2}{*}{$\begin{array}{c}\text { Before } \\
\text { quinidine }\end{array}$} & \multicolumn{3}{|c|}{$\begin{array}{l}\text { Minutes after initiation } \\
\text { of quinidine infusion }\end{array}$} & \multirow{2}{*}{$\begin{array}{l}\text { Maximum } \\
\text { change }\end{array}$} \\
\hline & & & & 5 & 15 & 25 & \\
\hline \multirow[t]{6}{*}{1} & \multirow[t]{6}{*}{590} & $\mathrm{AH}$ & 75 & 80 & 85 & 80 & +10 \\
\hline & & HV & 45 & 45 & 50 & 52 & +7 \\
\hline & & QT & 285 & 370 & 390 & 390 & +105 \\
\hline & & RCL & 990 & 550 & 700 & 670 & -220 \\
\hline & & DCL & 640 & 640 & 645 & 645 & +5 \\
\hline & & MBP & $84^{\circ}$ & 72 & 75 & 74 & -12 \\
\hline \multirow[t]{6}{*}{2} & \multirow[t]{6}{*}{480} & $\mathrm{AH}$ & 85 & 85 & 100 & 100 & +15 \\
\hline & & $\mathrm{HV}$ & 42 & 45 & 55 & 55 & +13 \\
\hline & & QT & 330 & 340 & 360 & 370 & +40 \\
\hline & & RCL & 1,190 & 1,040 & 1,040 & 1,050 & -150 \\
\hline & & DCL & 530 & 540 & 570 & 570 & +40 \\
\hline & & MBP & 72 & 79 & 64 & 66 & -8 \\
\hline \multirow[t]{6}{*}{3} & \multirow[t]{6}{*}{630} & $\mathrm{AH}$ & 110 & 115 & 115 & 115 & +5 \\
\hline & & HV & 45 & 50 & 55 & 60 & +15 \\
\hline & & QT & 325 & 365 & 415 & 435 & +110 \\
\hline & & RCL & 675 & 645 & 620 & 605 & -70 \\
\hline & & DCL & 685 & 700 & 755 & 740 & +70 \\
\hline & & MBP & 83 & 84 & 77 & 81 & -6 \\
\hline \multirow[t]{6}{*}{4} & \multirow[t]{6}{*}{515} & $\mathrm{AH}$ & 115 & 120 & 125 & 125 & +10 \\
\hline & & HV & 47 & 45 & 50 & 55 & +8 \\
\hline & & QT & 315 & 340 & 380 & 400 & +85 \\
\hline & & RCL & 700 & 620 & 625 & 520 & -180 \\
\hline & & DCL & 540 & 542 & 540 & 550 & +10 \\
\hline & & MBP & 113 & 110 & 97 & 98 & -15 \\
\hline \multirow[t]{6}{*}{5} & \multirow[t]{6}{*}{670} & $\mathrm{AH}$ & 100 & 105 & 115 & 115 & +15 \\
\hline & & HV & 40 & 40 & 42 & 40 & +2 \\
\hline & & QT & 335 & 460 & 475 & 475 & +140 \\
\hline & & RCL & 680 & 650 & 590 & 585 & -95 \\
\hline & & DCL & - & - & - & - & - \\
\hline & & MBP & 105 & 103 & 95 & 96 & -9 \\
\hline
\end{tabular}

* Electrophysiological intervals in ms, blood pressure in millimeters of mercury.

\$ Atrial pacing was performed during these electrophysiological measurements (except during recording of the spontaneous donor atrial cycle length) at a cycle length 25-50 ms shorter than the original spontaneous cycle length.

§Abbreviations: QT, QT interval; RCL, recipient atrial cycle length; DCL, donor atrial cycle length; MBP, mean central aortic blood pressure.

right basilic, or a femoral vein. In the cardiac recipients, as previously reported (7), stable pacing of the donor atrium required looping of the catheter within the atrium in such a way that the distal pair of pacing electrodes were applied to the high anterolateral donor right atrial wall. His bundle recordings were achieved by advancing a $7 \mathrm{~F}$ tripolar or a $5 \mathrm{~F}$ bipolar His bundle recording catheter across the tricuspid valve to the vicinity of the common bundle. Three surface electrocardiograph leads ( $I, a V F$, and $V_{1}$ ) were recorded simultaneously with the atrial and His bundle electrograms. Signals from the electrode catheters were transmitted to the AC input of an electrocardiograph amplifier with filter frequencies set between 40 and $500 \mathrm{~Hz}$. Atrial electrograms from both the remnant recipient atrium and the implanted donor atrium were recorded. Data were displayed on a switched-beam oscilloscope and recorded on photographic paper at a speed of $100 \mathrm{~mm} / \mathrm{s}$. Pacing stimuli of $2-\mathrm{ms}$ durations were delivered by a Tektronix pulse generator (Tektronix, Inc., Beaverton, Oreg.) at twice the diastolic threshold. Stimuli were temporally varied by a programmable digital stimulator (M. Bloom, Philadelphia, Pa.). After baseline recordings of the $A H, H V$, and QT intervals and the spontaneous donor and recipient sinus cycle lengths, the sinus node recovery time was measured three times by atrial pacing at a cycle length of $430 \mathrm{~ms}$ for a 1-min duration, followed by abrupt termination of pacing. A base pacing cycle length 25-55 ms shorter than the spontaneous sinus cycle length was then chosen, and $\mathrm{AH}, \mathrm{HV}$, and QT inter- 

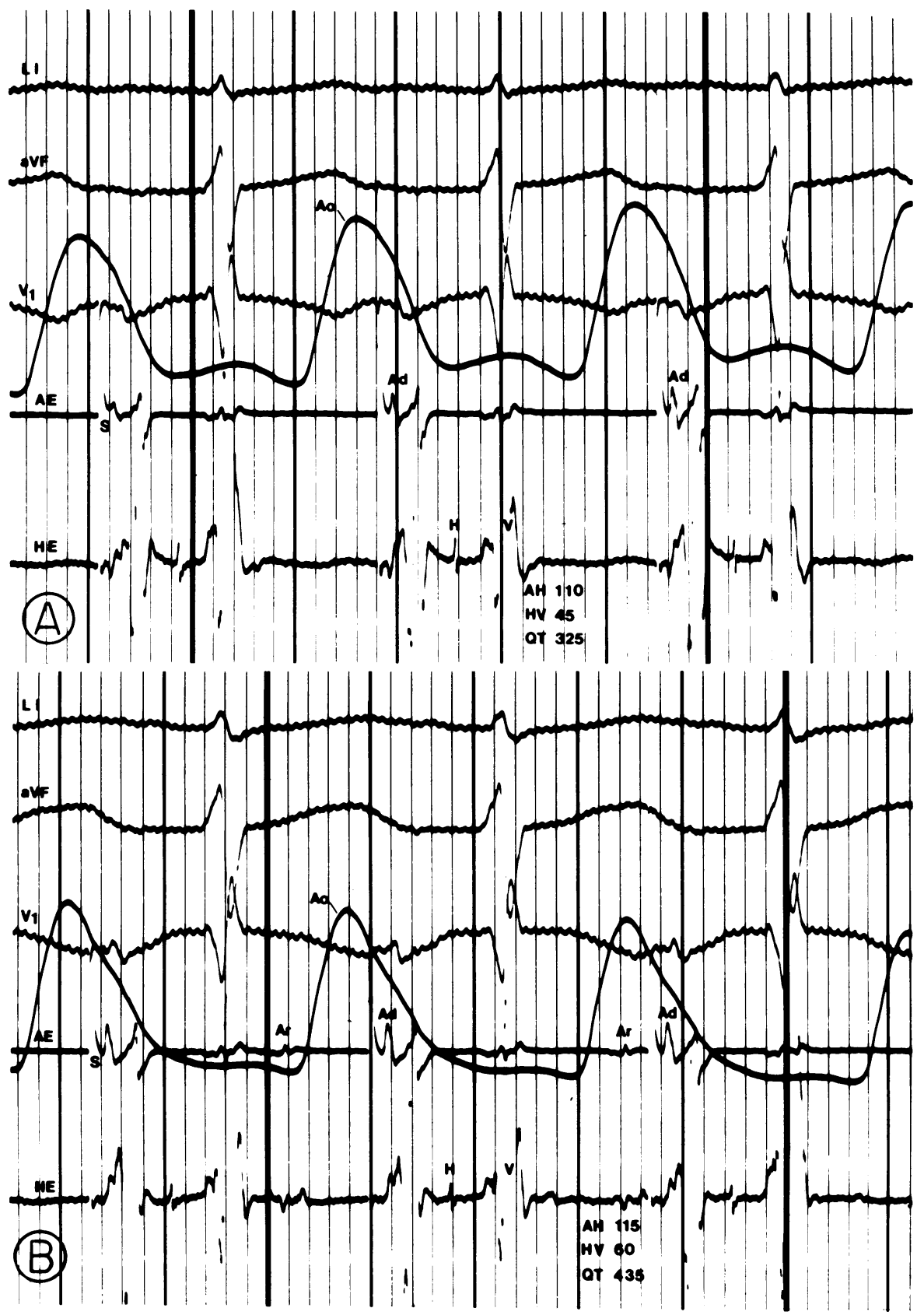

FIgURE 1 Tracings taken before (A) and $25 \mathrm{~min}$ after (B) initiation of quinidine infusion. The bold vertical time lines represent 1-s intervals. Three surface ECG leads (LI, aVF and $\mathrm{V}_{1}$ ), the aortic pulse (Ao), atrial electrogram (AE), and $\mathrm{His}$ bundle electrogram ( $\mathrm{HE}$ ) are shown. Although the recipient atrial electrogram ( $\mathrm{Ar}$ ) is well seen in panel $\mathrm{B}$, it occurred within the donor atrial complex (Ad) in the panel A tracing, and thus cannot be distinguished. " $\mathrm{H}$ " indicates the His bundle spike and " $\mathrm{V}$ " the ventricular depolarization. In this patient, the $\mathrm{AH}, \mathrm{HV}$, and QT intervals (milliseconds) increased respectively from 110,45 , and 325 to 115,60 , and 435 after quinidine administration.

vals were recorded at the spontaneous and the base paced heart rate. The atrial effective refractory period and the refractory periods of the atrioventricular node were determined using the extra-stimulus technique (12). After every eighth paced beat $\left(S_{1}\right)$, a premature stimulus $\left(S_{2}\right)$ was intro- duced. The $S_{1}-S_{2}$ interval was then reduced by 10 -msdecrements until the effective refractory period of the atrium was reached. The atrial effective refractory period was defined as the longest $S_{1}-S_{2}$ interval at which $S_{2}$ failed to depolarize the atrium. The $\mathrm{AV}$ nodal functional refractory period was 

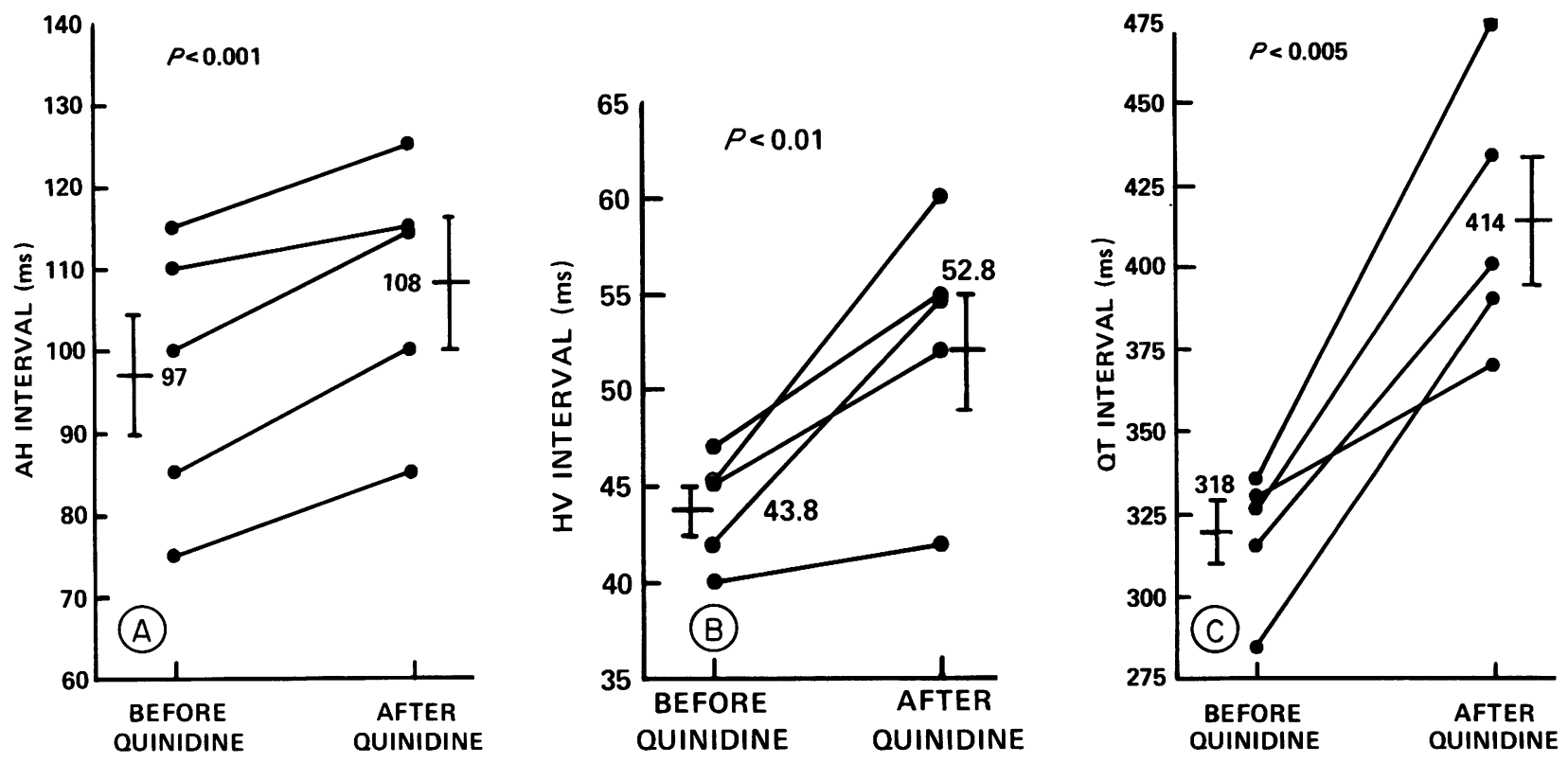

FIGURE 2 Conduction intervals before and after quinidine infusion (Table I). (A) All five patients had a significant rise in the AH conduction time after quinidine $(P<0.001)$. The mean change was $+11 \mathrm{~ms}$. The $P$ values, means, and SEMs are indicated in this and subsequent graphs. $(B)$ The $\mathrm{HV}$ interval increased after quinidine administration in all patients, and the mean change of $+9 \mathrm{~ms}$ was significant $(P<0.001)$. $(C)$ The QT interval increased significantly $(P<0.005)$ in all five patients by a mean of $+96 \mathrm{~ms}$ when measured at a constant paced rate.

defined as the shortest $\mathrm{H}_{1}-\mathrm{H}_{2}$ interval achieved, and the AV nodal effective refractory period was defined as the longest $A_{1}-A_{2}$ at which $A_{2}$ failed to conduct through the AV node to produce a His bundle potential. The spontaneous donor and recipient atrial cycle lengths were recorded as the average, to the nearest $5 \mathrm{~ms}$, of 15 sequential atrial cycles at each data interval. Central aortic blood pressure was measured through a PE 160 catheter placed transfemorally and connected to a Statham P23DB transducer (Statham Instruments Div., Gould Inc., Oxnard, Calif.)

After control measurements, quinidine gluconate salt, in a solution of $16 \mathrm{mg} / \mathrm{cm}^{3}$ of $5 \%$ dextrose and water, was administered to a total dose of $10 \mathrm{mg} / \mathrm{kg}$ by constant intravenous infusion over $20 \mathrm{~min}$. The $\mathrm{AH}, \mathrm{HV}$, and QT intervals, the sinus cycle lengths, and the blood pressure were then remeasured during spontaneous sinus rhythm and during pacing at the previously selected base pacing cycle length at 5,15 , and $25 \mathrm{~min}$ after initiation of the infusion. Repeat sinus node recovery times and refractory studies of the AV conduction system were accomplished at $30 \mathrm{~min}$ after the initiation of the infusion. Blood samples were obtained for plasma quinidine determinations before, and at $5,15,25$, 30 , and $40 \mathrm{~min}$ after the start of drug administration. Quinidine was assayed by the benzene-extraction technique (13).

To confirm persistence of functional cardiac denervation, the day before this investigation all five subjects had shown a delayed heart rate response, in onset and offset, to treadmill exercise testing, and after the study showed absence of a rate response to $1 \mathrm{mg}$ atropine administered intravenously.

Differences between electrophysiologic measurements recorded before and after quinidine administration were analyzed by the two-tailed Student's $t$ test for paired data.

\section{RESULTS}

Conduction intervals. Table I and Fig. 1 show quinidine's effects upon cardiac conduction intervals during base-rate atrial pacing. In general, maximum changes in the $\mathrm{AH}, \mathrm{HV}$, and QT intervals were observed at 15 min of infusion, by which time they had reached a plateau. Maximum changes in these intervals are illustrated in Fig. 2. Despite the small number of patients, the postquinidine mean values were significantly different from control measurements. The $\mathrm{AH}$ interval increased in all five patients from $97 \pm 8$ to $108 \pm 7(\mathrm{SEM}) \mathrm{ms}(P<0.001)$. The HV interval was lengthened in all subjects from a mean of $43.8 \pm 1$ to $52.8 \pm 3 \mathrm{~ms}(P \leq 0.01)$. The QT interval also increased in all five patients from a mean of $318 \pm 9$ to $414 \pm 19 \mathrm{~ms}(P<0.005)$.

Effect on sinus nodes. At transplantation, the posterior walls of the recipient atria, with the sinus node intact, are left in place for attachment of the donor atria. Thus, both the recipient and the donor sinus nodes remain functional after transplantation. The implanted donor sinus node is denervated, while the remnant recipient node retains its neural innervation. Separate donor and recipient atrial depolarizations can be detected by surface and intracardiac electrocardiography (14). The effects of quinidine 

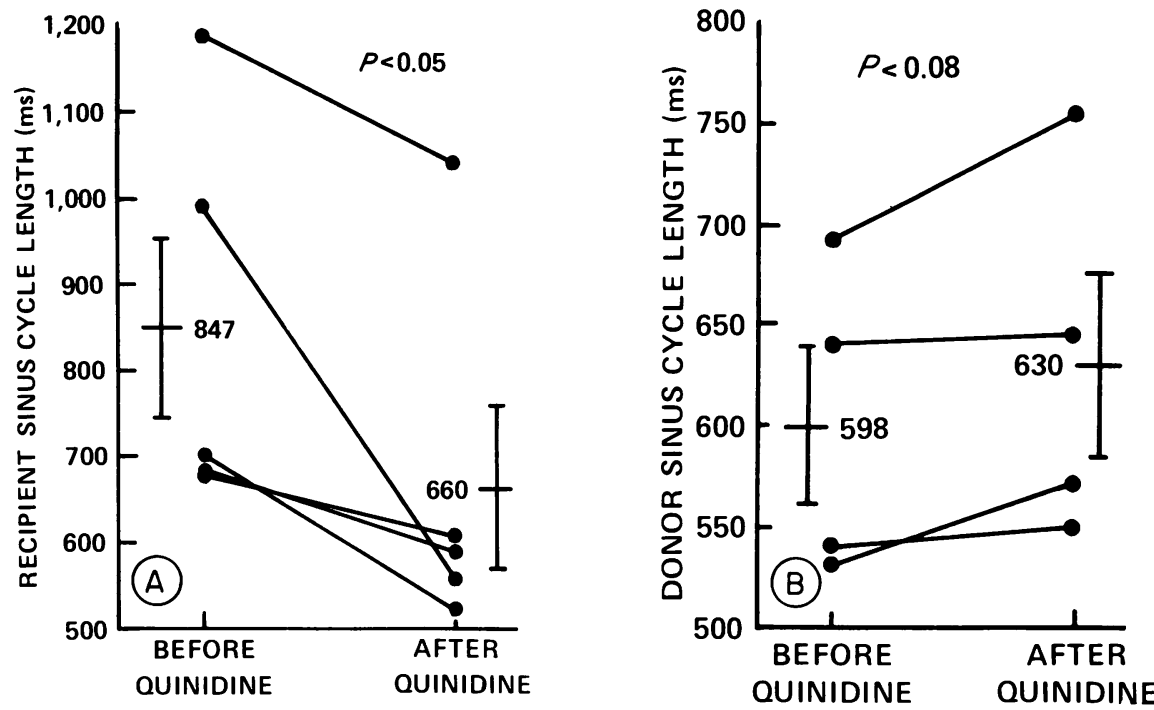

Figure 3 (A) The recipient sinus cycle lengths before and after quinidine dosage are shown. Quinidine resulted in a significant $(P<0.05)$ fall in the cycle length (that is, an increased atrial rate) in the recipient atria of all five patients. $(B)$ The cycle length of the denervated donor sinus node was increased (slowed atrial rate) in the four transplant patients in whom sinus rate could be measured (see text).

upon sinus cycle lengths are shown in Table $I$ and Figs. 3 and 4 . While the recipient sinus cycle length decreased in all five patients after quinidine from a mean of $847 \pm 104$ to $660 \pm 96 \mathrm{~ms}$, the donor sinus cycle length increased in the four patients in whom it could be measured from $599 \pm 38$ to $630 \pm 56 \mathrm{~ms}$. (One of the patients has a chronic post-transplantation junctional rhythm due to permanent sinus node arrest.) The donor sinus node recovery time was minimally and inconsistently affected by quinidine (Table II).
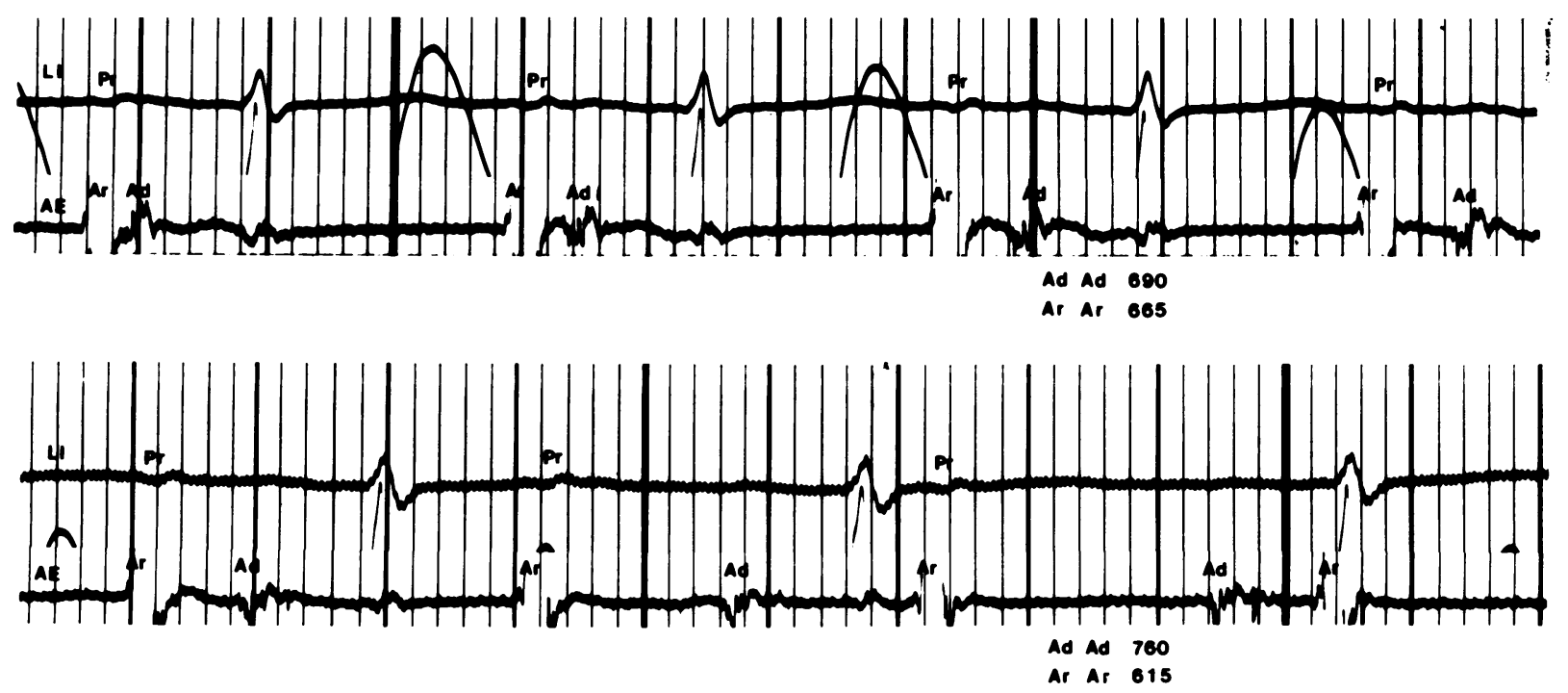

FIGURE 4 These tracings of Lead $1(\mathrm{Ll})$ and the atrial electrogram (AE) show the recipient (Ar) and donor (Ad) atrial depolarizations and the recipient $P$ wave $(\mathrm{Pr}$ ) (the donor $\mathrm{P}$ wave could not be distinguished in these surface tracings) before (A) and after (B) quinidine infusion. As noted, the donor atrial cycle length, Ad-Ad, increased from 690 to $760 \mathrm{~ms}$, whereas the recipient cycle length, Ar-Ar, decreased from 665 to $615 \mathrm{~ms}$. (The AE has been spliced underneath L1 in these illustrations, with the intervening recordings deleted, to facilitate interpretation. The listed cycle lengths represent direct measurements from the above tracings, rather than the mean cycle lengths obtained at this recording interval). 
TABLE II

Sinus Node Recovery Times*

\begin{tabular}{ccc}
\hline & \multicolumn{2}{c}{ Quinidine } \\
\cline { 2 - 3 } Patient & Before & After \\
\hline & & $m s$ \\
1 & 860 & \\
2 & 610 & 808 \\
3 & 1,095 & 615 \\
4 & 655 & 1,190 \\
5 & $2,700 \S$ & 650 \\
& & $1,350 \$$ \\
\hline
\end{tabular}

* Average of three recovery times obtained after $1 \mathrm{~min}$ of atrial pacing at a cycle length of $430 \mathrm{~ms}$.

$\$ 30$ min after initiation of infusion.

$\S$ These recovery times refer to the reemergence of this patient's junctional rhythm after atrial pacing.

Effect of atrial and AV nodal refractory periods. The atrial effective refractory period increased in all five patients from a mean value of $214 \pm 14$ to $241 \pm 11$ ms $(P<0.01)$ (Fig. 5). The AV nodal functional refractory period was variably affected; it increased in three of the patients, remained unchanged in one, and decreased in the fifth patient (Table III). The AV nodal effective refractory period and the refractory

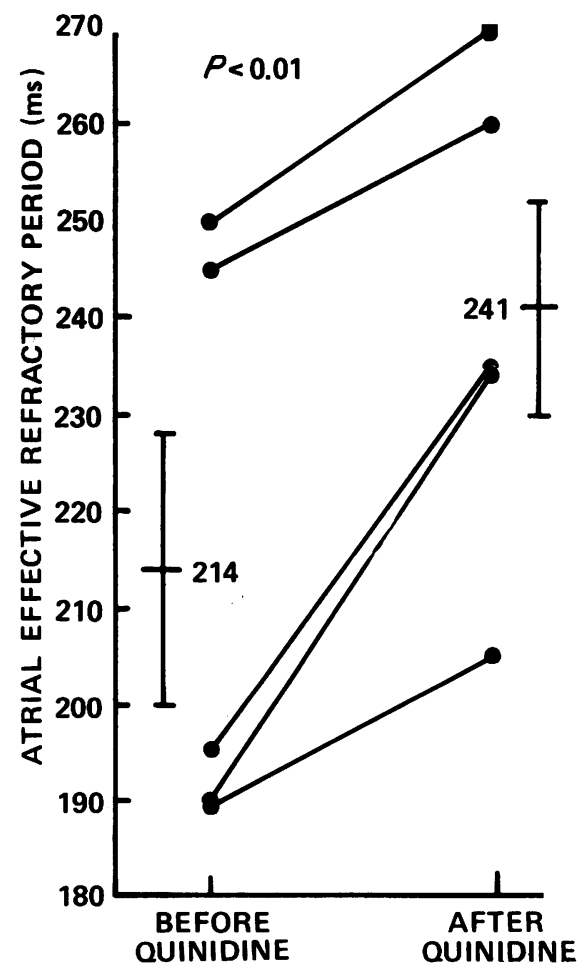

FIGURE 5 The atrial effective refractory period was significantly increased by $27 \mathrm{~ms}(P<0.01)$ after quinidine administration. periods of the His-Purkinje system could not be determined in any of the patients, due to earlier refractoriness higher in the conduction system.

Effect on blood pressure. Sequential changes in mean blood pressure are recorded in Table I. The average mean central aortic blood pressure fell from $91.4 \pm 7.6$ to $81.0 \pm 6.5(P<0.005)$ at its nadir after quinidine administration.

Plasma quinidine concentrations. Mean plasma quinidine levels at $5,15,25,30$, and $40 \mathrm{~min}$ after initiation of the infusion were $2.36,9.83,6.12,4.37$, and $3.95 \mu \mathrm{g} / \mathrm{ml}$, respectively. Although a true steadystate condition was not achieved at the time that the repeat refractory determinations and sinus node recovery measurements were made, the plasma quinidine concentrations had almost reached a plateau and the mean concentration of $4.37 \pm 0.449(\mathrm{SEM}) \mu \mathrm{g} / \mathrm{ml}$ (range $3.07-5.14 \mu \mathrm{g} / \mathrm{ml}$ ) is similar to the $4.6 \mu \mathrm{g} / \mathrm{ml}$ level reported by Josephson et al. (6) after intramuscular injections, and is within the range considered therapeutic for chronic oral therapy. One patient experienced a brief episode of nausea, but no other patient reported subjective side effects. Ventricular irritability was not encountered during or after the study, as determined by continuous electrocardiographic monitoring.

\section{DISCUSSION}

We have studied the denervated hearts of five cardiac transplant recipients to identify direct electrophysiologic effects of quinidine upon the human cardiac conduction system. Transplant recipients provide a model for the study of cardiac drug actions in a millieu free of direct autonomic nervous influences.

To support the contention that functional autonomic denervation persists in long-term human cardiac transplant survivors, we have shown that the present subjects', and other cardiac recipients', rate responses to exercise are sluggish, both in onset and offset, as is observed in animals with anatomic cardiac denervation (15). Furthermore, those long-term survivors who have suffered myocardial infarctions have not experienced cardiac pain. Finally, pharmacologic interventions with intravenous atropine and tyramine, and inhaled amyl nitrite, which result in tachycardia in subjects with normal cardiac innervation, produce no significant heart rate changes in transplant recipients $(7,15)$.

Studies of direct electrophysiologic effects in isolated tissue have shown that quinidine alters action potentials of the cells of the cardiac conduction system. Slowing of phase zero (upstroke) and delays of phase two (plateau) and phase three (rapid repolarization) of the action potential are seen (16). 
These effects are clinically evidenced by prolongation of the QRS complex and lengthening of the QT interval of the surface electrogram. In addition, quinidine reduces the rate of diastolic depolarization and inhibits action potentials elicited in early phase three (early in the relative refractory period). These drug actions would be expected to result in prolonged refractory periods, decreased conduction velocities, damped automaticity, and an antiarrhythmic effect in humans treated with quinidine. All of these expected actions, however, are not observed clinically; patients with therapeutic plasma quinidine concentrations, instead, usually show increased sinus rate and decreased AV nodal conduction time (6). Indirect, autonomically mediated effects of quinidine, which have been recognized since 1937, account for these unanticipated findings. Hiatt et al. (1) and Nathanson (2) established, in the experimental animal, that quinidine decreases cardiac vagal tone. James and Nadeau (4), using direct sinus node perfusion, demonstrated that quinidine blocks the effects of both vagal stimulation and acetylcholine infusion upon the sinus node and blocks adrenergic stimuli to a comparable degree. Other investigators have emphasized this sympatholytic action (16-18).

Thus, quinidine produces autonomic nervous system-mediated cardiac effects. These actions must account for the differences between our observations in transplant patients and those reported by Josephson et al. in patients with intact cardiac nerves (6). The quinidine levels which Josephson et al. recorded in their electrophysiologic study are similar to the concentrations which we attained. We make a more detailed comparison of our findings in cardiac transplant recipients with their findings in intact humans below (Table IV).

The innervated sinus node of the recipient's excised heart remains present and intact, and serves as a "control" for comparison with the denervated donor sinus node. This innervated node significantly increased its rate of depolarization after quinidine administration (Fig. 3A) which is consistent with the findings of Josephson et al. of an increased heart rate after intramuscular quinidine administration. On the other hand, the denervated donor sinus rate was slowed by quinidine in all four patients in whom sinus rate could be measured (Fig. 3B). Although this change fell short of statistical significance, $(P<0.08)$, the consistency of the response holds greater weight than statistical analysis in such a small sample. This comparison of the two sinus nodes within the same patient clearly separates quinidine's direct effect, which is to depress sinus node autonomaticity, from its autonomically mediated acceleratory effect on the sinus node. James and Nadeau (4) concluded, from their direct sinus node perfusion studies in the anes-
TABLE III

AV Nodal Functional Refractory Periods

\begin{tabular}{ccc}
\hline & \multicolumn{2}{c}{ Quinidine } \\
\cline { 2 - 3 } Patient & Before & After \\
\hline & & $m s$ \\
1 & 325 & 345 \\
2 & 350 & 350 \\
3 & 390 & 450 \\
4 & 375 & 340 \\
5 & 445 & 460 \\
\hline
\end{tabular}

thetized dog, that quinidine's anticholinergic actions were opposing influences of nearly comparable magnitude at therapeutic levels of the drug. Our results indicate that, in the unanesthetized human, quinidine's predominant action upon the innervated sinus node is autonomically mediated and that this autonomic effect outweighs the direct sinus nodal-depressant effect. Sinus node recovery times after quinidine did not reflect this depression of sinus nodal automaticity. However, factors other than automaticity affect the postpacing recovery times, such as perinodal entrance and exit block $(19,20)$, local metabolic factors $(21,22)$, and fiber stretch (22).

Because the mean blood pressure fell by approximately $10 \mathrm{~mm} \mathrm{Hg}$ in this group of subjects, the possibility of a resultant reflex sympathetically mediated acceleration of the innervated recipient sinus rate (rather than a vagolytic quinidine effect) cannot be entirely dismissed. However, the occurrence of recipient atrial acceleration in the absence of a significant fall, and even in the presence of a rise, in blood pressure at several data points (Table I, patient 2 at $5 \mathrm{~min}$; patient 3 at 5 and $25 \mathrm{~min}$, patient 4 at $5 \mathrm{~min}$, and patient 5 at $5 \mathrm{~min}$ after initiation of quinidine infusion) is contrary to this explanation.

AV nodal conduction time, which decreases in normally innervated patients after the administration of

TABLE IV

Electrophysiologic Effects of Quinidine in Transplant Recipients Compared with Normal Patients*

\begin{tabular}{lll}
\hline \multicolumn{1}{c}{ Location } & Normal & Transplant \\
\hline Sinus node & $\downarrow \mathrm{CL}$ & $\uparrow \mathrm{CL}$ \\
AV node $\downarrow$ & $\downarrow \mathrm{CT}$ & $\uparrow \mathrm{CT}$ \\
Atrium & $\uparrow \mathrm{ERP}$ & $\uparrow \mathrm{ERP}$ \\
His-Purkinje system & $\uparrow \mathrm{CT}$ & $\uparrow \mathrm{CT}$ \\
\hline
\end{tabular}

CL, cycle length; CT, conduction time; ERP, effective refractory period; $\downarrow$, decreased; $\uparrow$, increased.

* Taken from Josephson et al. (6).

$\ddagger$ During atrial pacing. 
quinidine, increased in the transplant patients (Fig. $2 A)$, indicating that quinidine directly slows AV nodal conduction but that its predominant effect in intact man is to enhance AV nodal conduction by an autonomically mediated mechanism. Once again it can be argued that the mild reduction in blood pressure reported by Josephson et al. (6) (approximately $10 \mathrm{~mm}$ $\mathrm{Hg}$, systolic) accounted for the reduction they noted in the AH interval in his innervated patients. While it seems just as likely that vagolytic quinidine effects were responsible, it was not within the scope of their study or the present study to differentiate between these two possibilities.

Our transplant recipients and Josephson and colleagues' normal patients showed similar changes in His-Purkinje conduction time after quinidine administration. Prolongation of the $\mathrm{HV}$ interval by quinidine, then, appears to be a direct effect, as it occurs in the absence of autonomic innervation. The possibility still exists that additional autonomic effects of quinidine might influence the human HisPurkinje system, which has sympathetic and histologically demonstrated cholinergic innervation (23). However, since our subjects showed HV interval changes of a magnitude similar to those of patients with intact autonomic innervation, it would appear that the major portion of quinidine's effect upon the HisPurkinje system is direct.

The magnitude of increase in the atrial effective refractory period after quinidine in transplant recipients (Fig. 5) was similar to that which occurs in normally innervated patients. This finding documents the existence of a direct drug effect upon the atrium of man. Quinidine's anticholinergic activity should also prolong refractoriness of atrial tissue. Although both mechanisms probably act in concert in intact man, a similarity in the degree of change in innervated and denervated hearts favors a predominance of the direct effect.

We have drawn four conclusions regarding the cardiac conduction system actions of quinidine in man. These conclusions are supported by previous animal investigations, and represent the first clear separation of quinidine's direct activity and its autonomically mediated activity in man. First, the enhancement of sinus rate seen after quinidine administration in man is a neurally mediated effect, dependent upon an intact cardiac autonomic supply; quinidine's direct effect is to slow the rate of depolarization of the sinus node. Second, the net enhancement of AV nodal conduction by quinidine in man is most likely due to an autonomic effect which opposes and outweighs its direct slowing effect upon the AV node. Third, quinidine decreases His-Purkinje conduction by a direct action which can occur independently of autonomic influences. Fourth, the cardiac autonomic nerv- ous system is not critically involved in quinidine's prolongation of the atrial refractory period.

\section{ACKNOWLEDGMENTS}

This work was supported in part by National Institutes of Health grant HL-5866 and Program Project grant 1-PO1-HL15833.

\section{REFERENCES}

1. Hiatt, E., D. Brown, G. Quinn, and K. MacDuffie. 1945. The blocking action of the cinchona alkaloids and certain related compounds in the cardio-inhibitory vagus endings of the dog. J. Pharmacol. Exp. Ther. 85: $55-58$.

2. Nathanson, M. H. 1934. Modification of vagus inhibition of the heart by quinidine. Proc. Soc. Exp. Biol. Med. 31: $1234-1236$.

3. Wallace, A. G., R. E. Cline, W. C. Sealy, W. G. Young, Jr. and W. G. Troyer, Jr. 1966. Electrophysiologic effects of quinidine. Studies using chronically implanted electrodes in awake dogs with and without cardiac denervation. Circ. Res. 19: 960-969.

4. James, T., and R. A. Nadeau. 1964. The mechanism of action of quinidine on the sinus node studied by direct perfusion through its artery. Am. Heart J. 67: 804811 .

5. Hirschfeld, D. S., C. T. Veda, M. Rowland, and M. M. Scheinman. 1974. Clinical and electrophysiologic effects of intravenous quinidine in man. Circulation. 50: (Suppl. III): 111-230. (Abstr.)

6. Josephson, M. E., S. F. Seides, W. P. Batsford, G. M. Weisfogel, M. Akhtar, A. R. Caracta. S. H. Lau, and A. N. Damato. 1974. The electrophysiologic effects of intramuscular quinidine on the atrioventricular conducting system in man. Am. Heart J. 87: 55-64.

7. Cannom, D. S., A. F. Graham, and D. C. Harrison. 1973. Electrophysiological studies in the denervated transplanted human heart. Response to atrial pacing and atropine. Circ. Res. 32: 268-278.

8. Goodman, D. J., R. M. Rossen, D. S. Cannom, A. K. Rider, and D. C. Harrison. 1975. Effect of digoxin on atrioventricular conduction: Studies in patients with and without cardiac autonomic innervation. Circulation. 51: 251256.

9. Goodman, D. J., R. M. Rossen, R. E. Ingham, A. K. Rider, and D. C. Harrison. 1975. Sinus node function in the denervated human heart. Effect of digitalis. Br. Heart J. 37: $612-618$.

10. Cannom, D. S., A. K. Rider, E. B. Stinson, and D. C. Harrison. 1975. Electrophysiologic studies in the denervated transplanted human heart. II. Response to norepinephrine, isoproterenol and propranolol. Am. Heart J. 36: 859-866.

11. Goodman, D. J., R. M. Rossen, A. K. Rider, and D. C. Harrison. 1976. The effect of cycle length on cardiac refractory periods in the denervated human heart. Am. Heart J. 91: 332-338.

12. Krayer, O., J. J. Mandoki, and C. Mendez. 1951. Studies on veratrum alkaloids. XVI. The action of epinephrine and of veratramine on the functional refractory period of the atrioventricular transmission in the heart-lung preparation of the dog. J. Pharmacol. Exp. Ther. 103: 412-419.

13. Cramer, G., and B. Isaksson. 1963. Quantitative determination of quinidine in plasma. Scand. J. Clin. Lab. Invest. 15: 553-556.

14. Stinson, E. B., J. S. Schroeder, R. B. Griepp, N. E. Shum- 
way, and E. Dong, Jr. 1972. Observations on the behavior of recipient atria following cardiac transplantation in man. Am. J. Cardiol. 30: 615-622.

15. Stinson, E. B., R. B. Griepp, J. S. Schroeder, E. Dong, Jr. and N. E. Shumway. 1972. Hemodynamic observations one and two years after cardiac transplantation in man. Circulation. 45: 1183-1194.

16. Conn, H. L., Jr., and R. J. Luchi. 1964. Some cellular and metabolic considerations relating to the action of quinidine as a prototype antiarrthythmic agent. Am.J. Med. 37: 685-699.

17. Hiatt, E. P. 1950. Sympatholytic effects of quinine and quinidine. Am. J. Physiol. 160: 212-216.

18. Luchi, R. J., J. Helwig Jr., and H. L. Conn Jr. 1963. Quinidine toxicity and its treatment. An experimental study. Am. Heart J. 65: 340-348.

19. Mandel, W., H. Hayakawa, R. Danzig, and H. S. Marcus.
1971. Evaluation of sinoatrial node function in man by overdrive suppression. Circulation. 44: 59-66.

20. Strauss, H. C., A. L. Saroff, J. T. Bigger Jr., and E. G. V. Giardina. 1973. Premature atrial stimulation as a key to the understanding of sino atrial conduction in man. Presentation of data and critical review of the literature. Circulation. 47: 86-93.

21. Narula, O. S., P. Samet, and R. P. Javier. 1972. Significance of the sinus-node recovery time. Circulation. 45: $140-158$.

22. Hoffman, B. F., and P. F. Cranefield. 1960. Electrophysiology of the Heart. McGraw-Hill, Inc., New York. $323 \mathrm{pp}$.

23. Kent, K. M., S. E. Epstein, T. Cooper, and D. M. Jacobowitz. 1974. Cholinergic innervation of the canine and human ventricular conducting system. Anatomic and electrophysiologic correlations. Circulation. 50: 948-955. 